\title{
Effect of Concrete Admixtures on Structural Properties and Corrosion Resistance of Steel Reinforcements
}

\author{
Ali Dad CHANDIO ${ }^{1 *}$, Shahid Hussain ABRO ${ }^{1}$, Asif Ahmed SHAIKH ${ }^{2}$, \\ Haseeb AHMED ${ }^{1}$, Baber FAROOQI ${ }^{1}$, Faraz MAHMOOD ${ }^{1}$, Yousra KHAN ${ }^{1}$, \\ Areeba SOHAIL ${ }^{1}$
}

\author{
${ }^{1}$ Department of Materials and Metallurgical Engineering, NED University of Engineering and Technology, Main University \\ Road, 75270. Karachi-Pakistan \\ ${ }^{2}$ Faculty of Chemical and Processes Engineering, NED University of Engineering and Technology, Main University Road, \\ 75270, Karachi-Pakistan
}

crossref http://dx.doi.org/10.5755/j02.ms.26369

Received 12 June 2020; accepted 05 January 2021

\begin{abstract}
Concrete structural properties are compromised largely due to corrosion susceptibility of steel reinforcements. This results in weakening and eventual failure of structures. Several strategies have been employed in past to control corrosion and increase mechanical strength of concretes, in particular for structural applications. In this study, fly ash and polypropylene fibers were utilized as the admixtures for preparation of concrete blocks with variable water-cement (w/c) ratios i.e. 0.45, 0.5 and 0.65 . Three different grades of cements were selected in this study namely OPC 43, OPC 53 and sulphate resistant one. Also, two different steel alloys were used i.e. ASTM-615 and ASTM-706, since both of them are very common reinforcement materials (rebars). The curing time of 56 consecutive days was employed before testing and characterization. The results suggest remarkable improvement in the mechanical properties of blocks upon the incorporation of admixtures. However, rebars exhibited highest corrosion rate in the presence of OPC 43 cement at w/c ratio of 0.65.

Keywords: rebars, concrete, admixtures, water-cement, corrosion.
\end{abstract}

\section{INTRODUCTION}

Concretes are being used in construction applications from centuries. While reinforced bars (mainly structural steels) have been embedded in order to meet the specific requirements of buildings. The failure of concretes caused mainly due to the corrosion of reinforced bars. Later, various researches suggested that concretes are prone to chloride attacks and carbonation causing deterioration of structural designs. Continuous improvements in material's properties were being studied since paleolithic age where researches were carried in order to protect them from possible defects. For many years, corrosion in rebars embedded in concretes remained a hot topic wherein 1958, it was practically observed in marine structures. Subsequently, the construction industry faced huge loss and, in some cases, the repair cost was estimated to exceed the initial construction cost. The durability and longevity of steel reinforced concrete has been a major concern. Durability of concrete confides in factors like porosity, strength of concrete, although these factors depend on water cement ratios [1-3]. The penetration of detrimental substances such as $\mathrm{CO}_{2}, \mathrm{O}_{2}$, chlorides and sulphates through the structures after hardening mainly causes pitting or uniform corrosion in reinforced structures [3-5].

The alteration in concrete's properties were facilitated by the application of admixtures, which are special additives other than cement, water, and aggregates. These additives played a vital role in subjecting enhanced mechanical and corrosion resistant properties.
Various researchers have been employed, which gave a comprehensive review about the corrosion inhibitors used in concrete such as introducing the idea of having 2 percent calcium nitrite by mass. Thereby increasing the threshold concentration of chloride and ultimately, reducing the rate of corrosion. Unfortunately, owing to lack of experience, there is no proper data on the cost-benefit analysis for increasing the properties, service life and durability of reinforced concrete structures that are exposed to harmful environmental conditions. However, one report suggested that the use of corrosion inhibitors or epoxy coated reinforcement can increase the cost of concrete structures by 8 percent, moreover, the literature suggested that hydrophobic coatings can also be beneficial in such cases [5-8]. Some common admixtures include: air-entraining admixtures, water-reducing admixtures, accelerating admixtures, corrosion inhibitors, shrinkage reducers, alkalisilica reactivity inhibitors, etc. [8-16]. Since, a large number of additives have been employed in order to alter the characteristics of concrete. Numerous classifications of additives are available such as accelerators, air entraining, anti washout and alkali aggregate reactivity inhibitors. Each admixture contributes according to its characteristics, such as providing strength to concrete, minimizing air content, increasing workability or decreasing the rate of reactivity. The materials used as admixtures include calcium chloride, sodium thiocyanate, tributyl phosphate salts of wood resins, cellulose and acrylic polymers [17-20]. Corrosion in reinforced concrete structures has been a common issue in

\footnotetext{
* Corresponding author. Tel.: +92-21-99261261.

E-mail address: alidad@neduet.edu.pk (A.D. Chandio)
} 
the construction sector. The idea for this work to eliminate the corrosion problem came up from available research data/literature. This was consisted of rebar coating, using a good number of additives in concrete and working on curing strategies individually. Thus, a combination of experiments was carried forward. The main goal was to enhance the corrosion resistance and structural properties of concrete without using the rebar coating method. Somehow, it was figured out with a conclusion by using a combination of some experiments, like using less number of additives compared to other experimental researches along with focusing on curing parameters. This concept brought a great impact especially economical one. Only two admixtures including i.e., fly ash and polypropylene fibers were used. The solid customized concrete was then cured with water for 56 days in continuation. With the strong combination of both the ideas, the resistance and strength were increased successfully. However, curing could be a time taking process but its impact over properties of concrete is remarkable.

Therefore, the work was carried in order to suggest an affordable and economical concretes. Simultaneous durability, shock and corrosion resistant properties were the main objectives too [21-27].

\section{EXPERIMENTAL DETAILS}

This study comprised the use of various materials including fly ash, duracrete fiber accompanied with three types of ordinary Portland cement (OPC-53 grade, OPC-43 grade and Sulphate resistant cement) from different industries, namely Lucky cement and Falcon cement as shown in Table 1. In total, the 54 samples of concretes were prepared according to different water to cement (w/c) ratios as shown in Table 1.

Table 1. The materials used for the study

\begin{tabular}{|l|c|c|c|c|}
\hline \multicolumn{1}{|c|}{ Cement } & $\begin{array}{c}\text { Reinforcement } \\
\text { bars }\end{array}$ & Aggregates* & Water & Admixtures* \\
\hline $\begin{array}{l}\text { IS-269:2015 } \\
\text { (OPC-lucky } \\
\text { cement) 53 } \\
\text { grade }\end{array}$ & $\begin{array}{c}\text { ASTM-615 } \\
\text { (grade 60) }\end{array}$ & $\begin{array}{c}\text { Fine } \\
\text { aggregates }\end{array}$ & $\begin{array}{c}\text { Tap } \\
\text { water }\end{array}$ & Fly ash \\
$\begin{array}{l}\text { OPC 43 } \\
\text { grade }\end{array}$ & $\begin{array}{c}\text { ASTM-706 } \\
\text { (grade 60) }\end{array}$ & $\begin{array}{c}\text { Coarse } \\
\text { aggregates }\end{array}$ & $\begin{array}{c}\text { Tap } \\
\text { water }\end{array}$ & $\begin{array}{c}\text { Duracrete } \\
\text { fiber }\end{array}$ \\
\hline $\begin{array}{l}\text { Sulphate } \\
\text { resistant } \\
\text { cement }\end{array}$ & $\begin{array}{c}\text { ASTM A- } \\
\text { 615/706 } \\
\text { (grade 60) }\end{array}$ & $\begin{array}{c}\text { Fine } \\
\text { aggregates }\end{array}$ & $\begin{array}{c}\text { Tap } \\
\text { water }\end{array}$ & $\begin{array}{c}\text { Fly ash/ } \\
\text { duracrete }\end{array}$ \\
\hline * aggregates and admixtures were used with every cement. \\
\hline
\end{tabular}

Table 2. Ratio of constituents for M50

\begin{tabular}{|c|c|c|c|}
\hline Grade & Cement & Fine aggregates & Coarse aggregates \\
\hline M50 & 1 & 2 & 4 \\
\hline
\end{tabular}

Each grade of cement contains about 3 similar samples mixed with tap water. Three w/c ratios were practiced with each grade of cement i.e. 0.45, 0.5, and 0.65. M50 (compressive strength of $50 \mathrm{~N} / \mathrm{mm}^{2}$ ) grade was followed which was later mixed with class-F fly ash and duracrete polypropylene fiber in cement paste in order to enhance the strength by making durable concretes and depreciate environmental attack. The ratio and quantity of constituent with respect to w/c ratio is shown in Table 3.
Table 3. Quantity of constituents with respect to w/c ratio

\begin{tabular}{|l|c|l|c|l|l|}
\hline $\begin{array}{l}\text { W/C } \\
\text { ratio }\end{array}$ & Cement & Water & Admixtures & $\begin{array}{l}\text { Fine } \\
\text { aggregates }\end{array}$ & $\begin{array}{l}\text { Coarse } \\
\text { aggregates }\end{array}$ \\
\hline 0.45 & $2 \mathrm{~kg}$ & 0.9 liter & $0.24 \mathrm{~kg}$ & $3 \mathrm{~kg}$ & $6 \mathrm{~kg}$ \\
\hline 0.5 & $2 \mathrm{~kg}$ & 1 liter & $0.24 \mathrm{~kg}$ & $3 \mathrm{~kg}$ & $6 \mathrm{~kg}$ \\
\hline 0.65 & $2 \mathrm{~kg}$ & 1.3 liter & $0.24 \mathrm{~kg}$ & $3 \mathrm{~kg}$ & $6 \mathrm{~kg}$ \\
\hline
\end{tabular}

Table 4. The chemical composition of reinforced rebars (Ref. ASTM International Standards)

\begin{tabular}{|c|c|c|c|c|c|c|c|}
\hline Sample & C & Si & Mn & S & P & Cr & Fe \\
\hline ASTM-615 & 0.39 & 0.23 & 1.09 & 0.03 & 0.06 & 0.16 & 97.7 \\
\hline ASTM-706 & 0.45 & 0.21 & 0.86 & 0.04 & 0.03 & 0.31 & 97.7 \\
\hline
\end{tabular}

Table 5. The values for tensile yield strength of reinforced rebars (Ref. ASTM International Standards)

\begin{tabular}{|l|c|c|}
\hline Sample & Tensile strength, MPa & Yield strength, MPa \\
\hline ASTM-615 & 760 & 596 \\
\hline ASTM-706 & 751.19 & 581.27 \\
\hline
\end{tabular}

According to the American concrete institute (ACI 308), the standard of curing is normally followed for 28 days in which the concrete attains $90 \%$ of its strength. So, to maximize the compressive strength more, thus curing days up to 56 were increased and to observe results whether the idea really worked or not and it successfully did.

\subsection{Testing and characterization}

The sample was prepared as follows:

\subsubsection{Concrete}

All the different ratios of concrete samples were made by using cement, fine aggregates, coarse aggregates, fly ash, polypropylene fibers, rebar and fresh water. The $6 \times 6$ inches steel boxes were made in which concrete material was casted. All the concrete ingredients were mixed according to the given proportions mentioned in table according to the M50 standard (Table 1) and were poured in the steel boxes along with the rebar of both grades as shown in Table 4 along with mechanical properties (Table 5). After 24 hours, steel boxes were dismantled and concrete blocks were cured in water for 56 days.

\subsubsection{LPR test samples}

Steel bar was cut into small pieces, which were welded with copper wire individually. After that, each sample was cold mounted with epoxy resin for further grinding and polishing purpose. The polished samples were one by one tested by putting it in a $500 \mathrm{ml}$ jar filled with the required salts proportions of concrete ratios.

\subsubsection{Helium porosimeter samples}

Each ratio of concrete block was cut in cylindrical shape by cutting machine according to the dimensions required to fit in the apparatus i.e., Helium porosimeter for testing porosity level.

The experimental work went through multiple characterization techniques. The chemical composition of reinforced bars (ASTM-615 and ASTM-706) was obtained by optical emission spectroscopy (SpectroMaxx LMM17 OES) followed by determination of tensile and compressive strength by universal testing machine. The composition of 
cement aggregates and fly ash was confirmed by X-ray diffraction technique (Panalytical, $\mathrm{X}$ PERT PRO). The alkalinity/acidity of water was determined by standard $\mathrm{pH}$ meter accompanied by TDS (total dissolved solid in water) meter. The porosity of concretes was characterized by helium porosimeter (HEP-E,Vinci technologies, France). Finally, the corrosion rate was determined by potentiostat (linear polarization resistance).

\subsection{Optical emission spectroscopy}

The chemical composition of both of the rebar steel alloys were carried out by using optical emission spectroscopy and results obtained are shown in Table 6 were in conformation with the standard compositions [6, 7] i.e. ASTM A-615.

Table 6. Confirmation of steel grade and associated compressive strength values for ASTM-615 obtained

\begin{tabular}{|c|l|c|l|c|}
\hline No. & Steel grade & $\begin{array}{c}\text { W/C } \\
\text { ratio }\end{array}$ & Type of cement & $\begin{array}{c}\text { Compressive } \\
\text { strength, MPa }\end{array}$ \\
\hline 1 & ASTM A-615 & 0.65 & OPC 43 grade & 58.10 \\
\hline 2 & ASTM A-615 & 0.50 & OPC 43 grade & 73.11 \\
\hline 3 & ASTM A-615 & 0.45 & OPC 43 grade & 102.94 \\
\hline 4 & ASTM A-615 & 0.65 & OPC 53 grade & 55.18 \\
\hline 5 & ASTM A-615 & 0.50 & OPC 53 grade & 74.59 \\
\hline 6 & ASTM A-615 & 0.45 & OPC 53 grade & 104.38 \\
\hline 7 & ASTM A-615 & 0.65 & Sulphate resistant & 51.35 \\
\hline 8 & ASTM A-615 & 0.50 & Sulphate resistant & 89.7 \\
\hline 9 & ASTM A-615 & 0.45 & Sulphate resistant & 117.15 \\
\hline
\end{tabular}

\subsection{Tensile testing}

The tensile strength testing for both reinforced rebars were carried out and the results obtained are shown in Table 7.

Table 7. Compressive strengths for ASTM-706

\begin{tabular}{|c|l|c|l|c|}
\hline No. & Steel grade & $\begin{array}{c}\text { W/C } \\
\text { ratio }\end{array}$ & Type of cement & $\begin{array}{c}\text { Compressive } \\
\text { strength, MPa }\end{array}$ \\
\hline 1 & ASTM A-706 & 0.65 & OPC 43 grade & 65.14 \\
\hline 2 & ASTM A-706 & 0.50 & OPC 43 grade & 87.516 \\
\hline 3 & ASTM A-706 & 0.45 & OPC 53 grade & 71.85 \\
\hline 4 & ASTM A-706 & 0.65 & OPC 53 grade & 94.80 \\
\hline 5 & ASTM A-706 & 0.50 & Sulphate resistant & 77.49 \\
\hline 6 & ASTM A-706 & 0.45 & Sulphate resistant & 106.57 \\
\hline
\end{tabular}

\section{RESULTS AND DISCUSSION}

\subsection{X-ray diffraction}

The XRD analysis was performed on OPC grade 43, OPC grade 53, sulphate resistant cement, fly ash, coarse and fine aggregates. The spectrum obtained confirms the presence of various compounds in the respective samples.

\subsubsection{OPC-43 grade}

The spectrum obtained confirms the presence of compounds namely calcium orthosilicate and tricalcium silicate and hence, by comparing with the standard research articles, confirming the availability for both calcium compounds. Beside these two compounds, there were also traces of magnesium, aluminum and iron in between the compounds. The compounds having the highest peaks cleared the fact for the maximum availability of calcium compounds in majority as shown in Fig. 1, therefore, confirming the OPC-43 grade. The highest peak of calcium lies in between the angle of 30 and 40 which is similar to the standard XRD results [8].

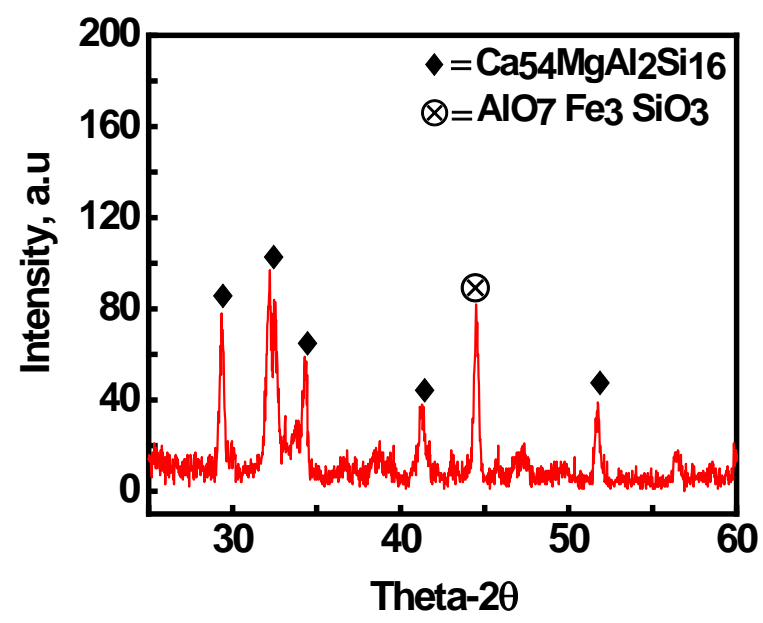

Fig. 1. XRD pattern of OPC-43 grade

The presence of sufficient amount of calcium compound like lime led to the formation of aluminates and silicates (e.g. tricalcium silicate) which provide strength to the cement [9].

\subsubsection{OPC-53 grade}

The peaks obtained showed the conformity of calcium orthosilicate and tricalcium silicate similar to OPC-43 grade as shown in Fig. 2.

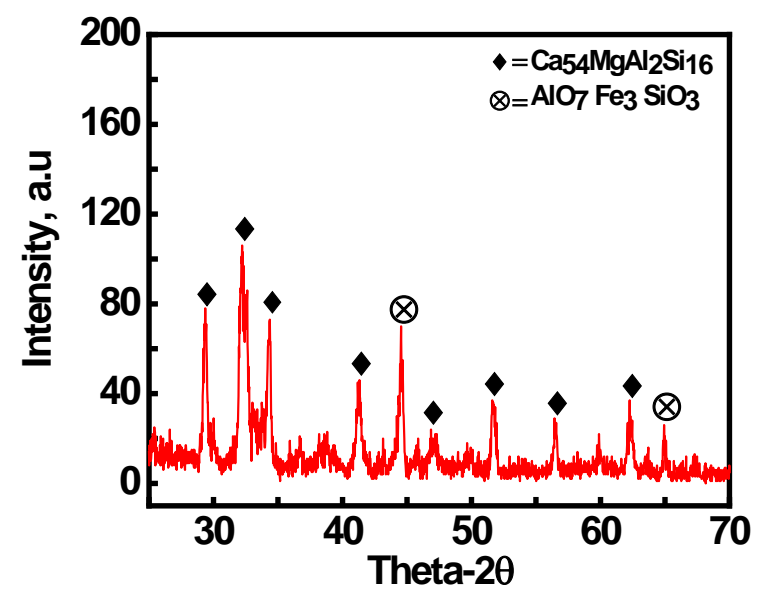

Fig. 2. XRD pattern of OPC-53 grade

The peaks were compared with the standard research articles confirming the availability for both of these calcium compounds having some traces of magnesium, aluminum and iron in between the compounds [8]. The higher score recorded in spectrum for magnesium, iron and aluminum made it distinguishable from OPC-43 grade. It has been observed that magnesia can lower the strength if it is more than $2 \%$, whereas, compound called ferrous tricalcium alumino ferrite at high temperature provides strength and hardness to the cement. The compounds having the highest peaks cleared the fact for the maximum availability of calcium compounds in majority and hence, confirmed the presence for OPC-53 grade. 


\subsubsection{Sulphate resistant cement}

The maximum availability of calcium silicate oxides was observed in the obtained spectrum as shown in Fig. 3, where peaks of the compound were present between the angle ranges of 27 to 35 degrees. Whereas, it differed from OPC-43 and OPC-53 cements by having tricalcium aluminate lower than 5 percent which restricted the formation of sulphate salts.

Hence, magnesium and aluminum were not observed in the generated peaks as witnessed in previous peaks. All the results were compared with the standards and composition of sulphate resistant cement was confirmed [10].

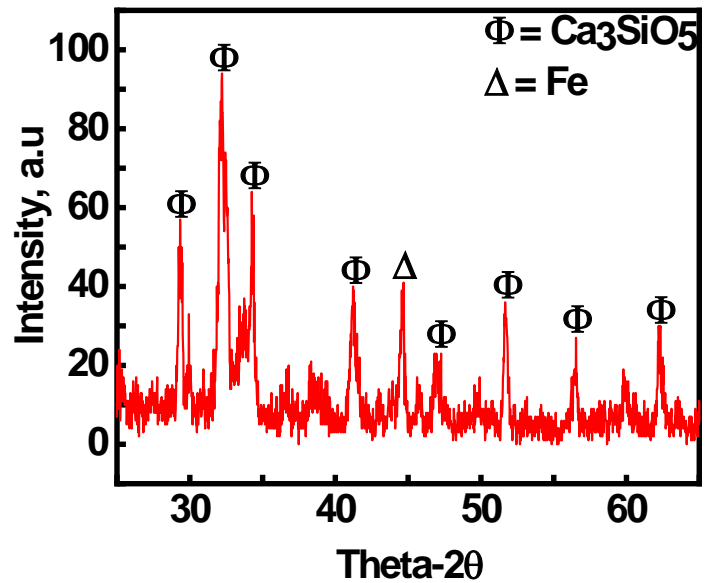

Fig. 3. XRD pattern of sulphate resistant cement

\subsubsection{Coarse aggregates}

The pattern confirmed the presence of compounds i.e. calcium compounds and silica where the former were in higher proportion having highest score peaks while the later scored second as shown in Fig. 4. The highest peak of calcium compound and silica were observed between the angles of 25 and 30 degree confirming the standard XRD of coarse aggregates [11].

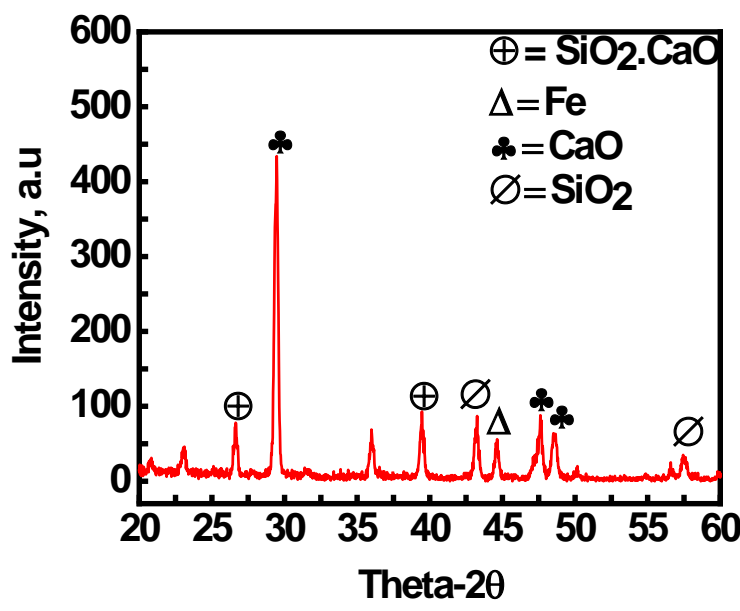

Fig. 4. XRD pattern of coarse aggregates

\subsubsection{Fine aggregates}

The XRD pattern confirmed the presence of silica in angles between 20 and 30 with traces of impurities like calcium, carbon and aluminum as shown in Fig. 5 . The availability of silica confirms the composition of sand i.e. quartz [12].

\subsubsection{Fly ash}

Fig. 6 shows XRD pattern with the highest peaks of carbon, calcium, alumina and mullite compounds having maximum score peaks of calcium, silicon and aluminum oxides. The XRD analysis confirmed the results for fly ash where the compounds made from carbon, aluminum, iron, silicon lied between $20^{\circ}$ and $30^{\circ}$ as well as $40^{\circ}$ and $50^{\circ}$ [13].

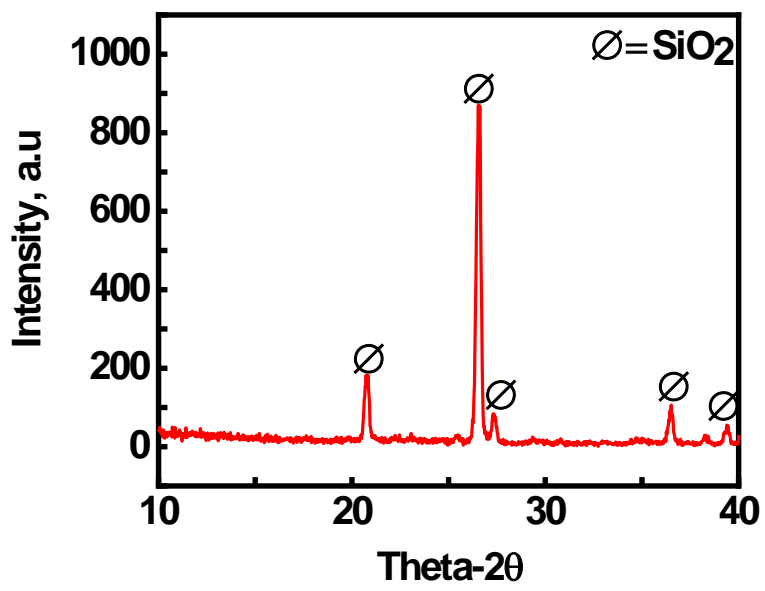

Fig. 5. XRD pattern of fine aggregates

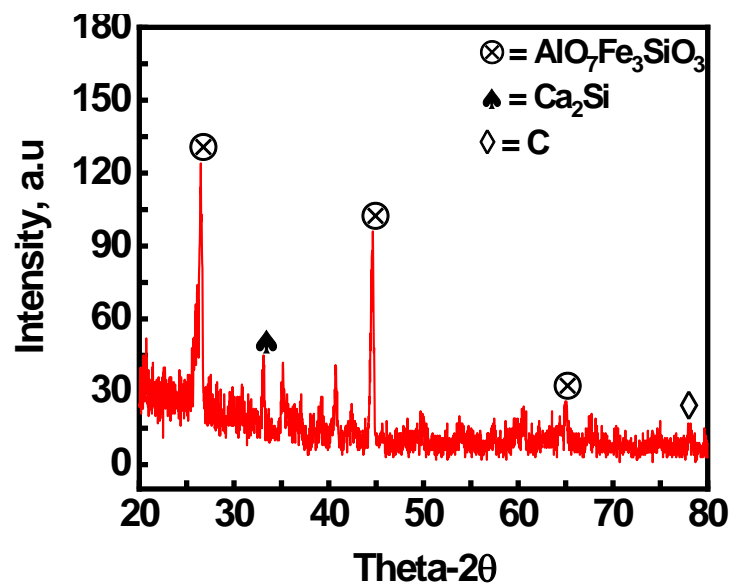

Fig. 6. XRD pattern of fly ash

\subsection{Total dissolved solid and $\mathrm{pH}$ analysis}

The $\mathrm{pH}$ for the tap water being used for the making of concretes was found to be 6.6 whereas the TDS for the tap water were found to be $511 \mathrm{ppm}$ whereas standard value for pure water should be $550 \mathrm{ppm}$, hence, the $\mathrm{pH}$ of water showed a little acidic behavior. Therefore, it was confirmed that the local water can be harmful for the durability and effective properties of concrete. Subsequently, it was the target issue regarding construction sector for establishing megastructures to minimize the harmful acidic effect and resistance towards corrosion [14].

\subsection{Compressive strength}

Compressive strength for reinforcement bars (ASTM 615 and ASTM 706) was computed by varying w/c ratios i.e., $0.65,0.45$ and 0.5 . The values obtained are shown in Fig. 8 and Fig. 9.

For instance, the schematic representation of compressive strength for rebars are shown in Fig. 7 and Fig. 8. According to the standard M50 grade of concrete having compressive strength up to $50 \mathrm{MPa}$, it was observed 
that-the compressive strength can be increased from 50 to $100 \%$ depending on the type of cement and different w/c ratios. These enhanced results were obtained only because of the greater curing time and special admixtures which amplified the properties of concrete. Normally less w/c ratio gave better results as compared to the concrete of higher water content due to less porosity and higher rate of particle bonding. From the experimental outcomes, it was observed that the sulphate resistant cement had maximum compressive strength as compared to the 43-grade cement with the lowest compressive strength and 53-grade cement with strength in between.

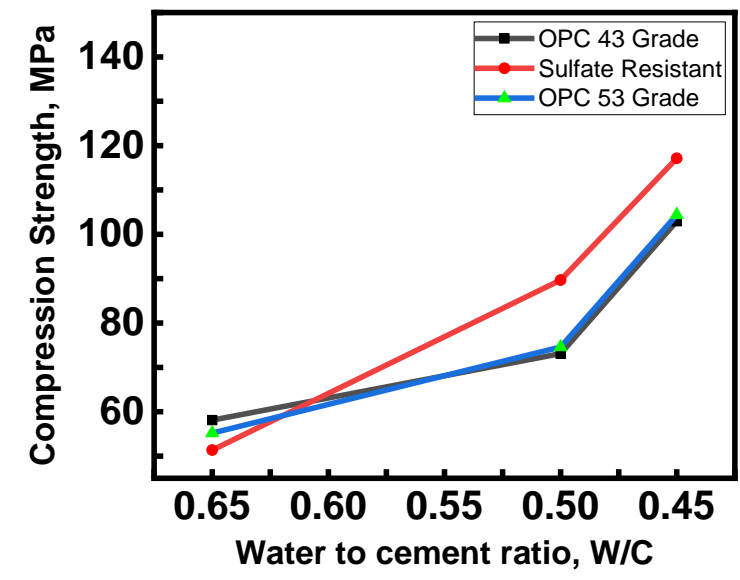

Fig. 7. The compressive strength of steel grade ASTM 615

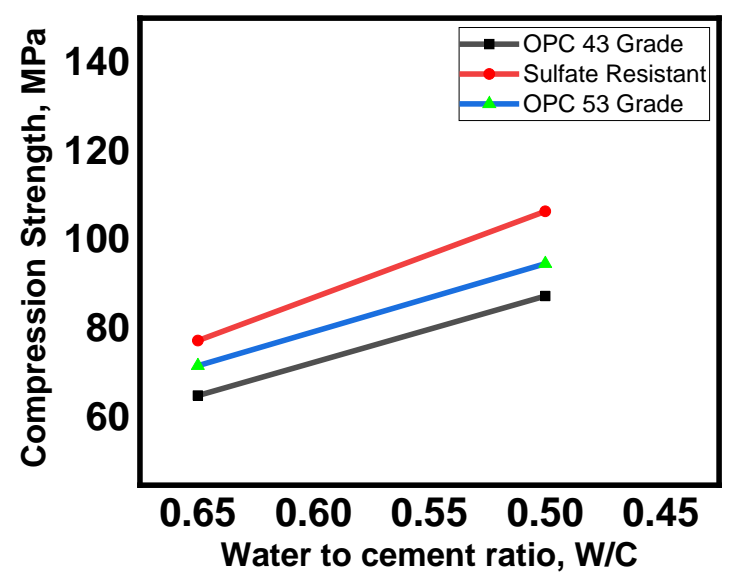

Fig. 8. The compressive strength of steel grade ASTM 706

Therefore, sulphate resistant cement is recommended for higher strength requirement with increased resistance towards harmful chemicals and better durability having a good economic advantage as well [15].

\subsection{Helium porosimeter}

The samples of concrete made by varying w/c ratios were tested for porosity by using helium porosimeter as shown in Table 8 whereas the graphical representation is illustrated in Fig. 9. The above-mentioned results indicate porosity values for concrete structure. The main objective is to compare porosity level with compressive strength. In this study, the porosity and compressive strength was found to be inversely proportional to each other i.e., higher the porosity level, lower will be the compressive strength as porosity level increases the water content in the concrete. The compressive strength of 0.65 ratios is considered low with a higher level of porosity.

Table 8. The porosity values of concrete made by varying w/c ratios

\begin{tabular}{|c|c|c|}
\hline No. & W/C ratio & Porosity, \% \\
\hline 1 & 0.65 & 15.16 \\
\hline 2 & 0.50 & 9.05 \\
\hline 3 & 0.45 & 6.1 \\
\hline
\end{tabular}

In case of fly ash, its particles act as miniature ball bearings in concrete structure improving its workability by producing cementitious compounds which act as a binder in concrete structure. The binder produced from fly ash reduces the interconnectivity of pores within the concrete structure resulting in decreased permeability. Fly ash provides great long term abrasion resistance due to its high strength which ultimately results in higher corrosion resistance.

Table 9. The corrosion rate for ASTM-615

\begin{tabular}{|c|c|c|}
\hline W/C ratio & Cements & Corrosion rate, mpy \\
\hline 0.65 & OPC-53 grade & 0.2543 \\
\hline 0.50 & OPC-53 grade & 0.2236 \\
\hline 0.45 & OPC-53 grade & 0.2116 \\
\hline 0.65 & OPC-43 grade & 1.6544 \\
\hline 0.50 & OPC-43 grade & 1.1494 \\
\hline 0.45 & OPC-43 grade & 0.2278 \\
\hline 0.65 & Sulphate resistant & 0.2989 \\
\hline 0.50 & Sulphate resistant & 0.2878 \\
\hline 0.45 & Sulphate resistant & 0.2643 \\
\hline
\end{tabular}

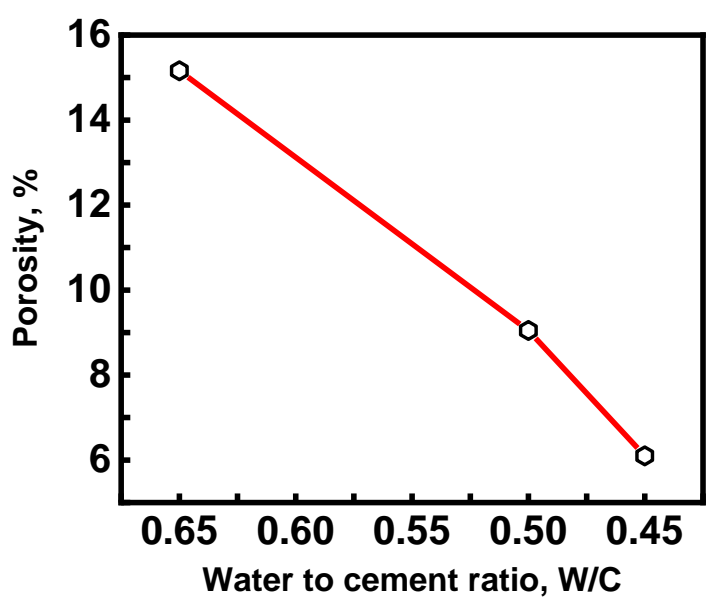

Fig. 9. The change in porosity with respect to water to cement ratio

Also, the porosity of 43 grade should be higher as compared to 53 grade and sulphate resistant cement. Higher the porosity, higher will be the chance of deterioration of concrete through chlorine, carbonates and attack [16]. Additionally, porosity also played a major role in compromising the strength of concretes. Considering the curing time, 56 days for each block gives maximum possible strength to concretes, but the porosity difference causes decrement in their compressive strength. The three different w/c ratios as-used in the project had a great impact on the strength of each concrete block. On the other hand, the polypropylene fibers are inert in nature making itself free from any chemical attack. If more aggressive chemicals 
penetrate the concrete structure, the concrete will always deteriorate first before fibers. The polypropylene fiber strongly holds the concrete structure and decrease the rate of segregation and cracking. The fiber contains high tensile strength and effectively increases the overall compressive strength of concrete structure eliminating the harmful chemicals from easily penetrating into the structure that result in corrosion. The plastic shrinkage cracking also decreases. In this way, any concrete structure can bear the tensile stresses by typical volume changes. The addition of polypropylene fibers to plain concrete increases its compressive strength from $4 \%$ to $17 \%$.

\subsection{Corrosion rate}

Diverse techniques have been employed in order to observe the deterioration of structural steel by chemical attack. Here in, corrosion rate for reinforced rebars was found by linear polarization resistant. Simultaneously, electrochemical reactions were accelerated when the sample was dipped in an electrolytically conducted solution (salts of sulphates, chlorides and carbonate in water). The process involved transfer of electrons from bare steel solid surface into anodic sites, hence steel's surface suffered from electron deficiency. The values obtained are shown in Table 10, Fig. 10 and Fig. 11 for ASTM-706. Similarly, the concrete block with maximum porosity tends to allow more sulphates and carbonates into it and hence, make rebars more prone to be chemically attacked.

Table 10. The corrosion rate for ASTM-706

\begin{tabular}{|c|c|c|}
\hline W/C ratio & Cements & Corrosion rate, mpy \\
\hline 0.65 & OPC-53 grade & 0.5563 \\
\hline 0.50 & OPC-53 grade & 0.2275 \\
\hline 0.45 & OPC-53 grade & 0.1826 \\
\hline 0.65 & OPC-43 grade & 0.3628 \\
\hline 0.50 & OPC-43 grade & 0.1832 \\
\hline 0.45 & OPC-43 grade & 0.1639 \\
\hline 0.65 & Sulphate resistant & 0.1677 \\
\hline 0.50 & Sulphate resistant & 0.1540 \\
\hline 0.45 & Sulphate resistant & 0.0592 \\
\hline
\end{tabular}

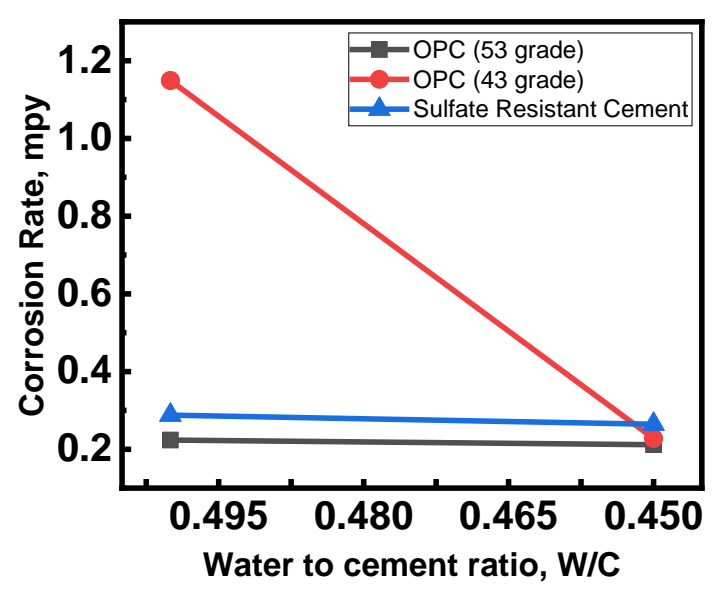

Fig. 10. The change in corrosion rate for ASTM-615

This phenomenon is described by [16] i.e. when porosity increases in the respective block, chlorides, sulphates and other active compounds penetrate into them and thereby, increase the susceptibility for corrosion attack as observed in OPC 53 grade cement with all W/C ratios.
Furthermore, the XRD spectrum has shown that OPC-53 and OPC-43 grades have active compounds present that cause rebars to degrade more rapidly whereas sulphate resistant cement tends to be more resistant to corrosion due to lesser susceptibility of sulphate penetration owing to porosity and no active compounds as evident from XRD pattern. The graphical representation of corrosion rate for ASTM-615 and ASTM-706 are shown in Fig. 10 and Fig. 11.

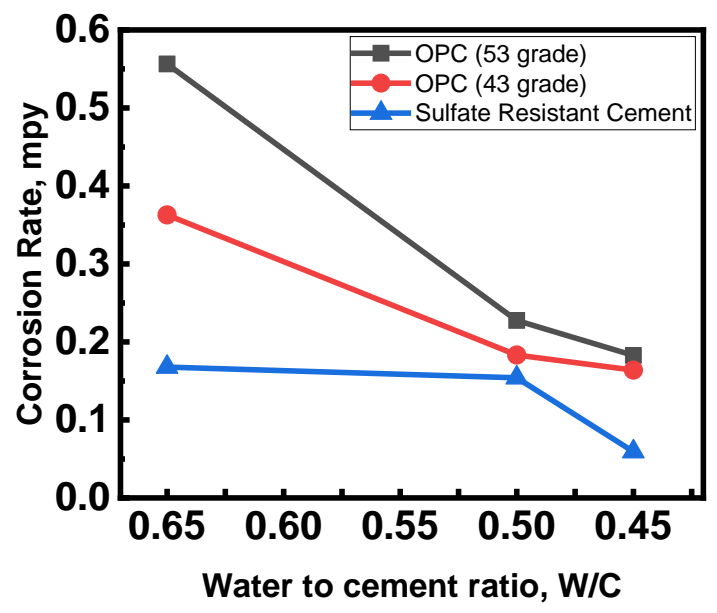

Fig. 11. The change in corrosion rate for ASTM-706

Fly ash increases hydration time while reducing the heat of hydration. As a result, the hydration time becomes greater which results in the elimination of gaining short term strength and will continuously increase the compressive strength in future. In this way, the durability and strength of concrete increase with more resistance towards penetration of harmful elements eliminating corrosion issue.

\section{CONCLUSIONS}

This study deals with the preparation of reinforced concretes upon incorporation of admixtures which includes fly ash and polypropylene fibers with higher curing time i.e., 56 days. Following are the concluding remarks- Upon the incorporation of sulphate resistant cement with suitable admixtures and curing time, the corrosion rate was reduced remarkably with increased compressive strength than that of counterpart cements. However, rebars exhibited highest corrosion rate in the presence of OPC 43 cement at w/c ratio of 0.65. In general, the remarkable improvement in the mechanical properties of blocks upon the incorporation of admixtures was observed. Nevertheless, the concrete blocks showed linear relationship between the porosity and w/c ratios.

\section{Acknowledgments}

Authors would like to thank the staff of the Department of Materials and Metallurgical Engineering for their support throughout this project.

\section{REFERENCES}

1. Zhu, X., Meng, Z., Liu, Y., Xu, L., Chen, Z. Entire process Simulation of Corrosion Due to the Ingress of Chloride Ions And $\mathrm{CO}_{2}$ in Concrete Advances in Materials Science and Engineering 2018 pp. 1-12.

https://doi.org/10.1155/2018/9254865 
2. Pack, W., Jung, S., Kang, W., Ann, Y., Kim, J. Assessment of Durability of Concrete Structure Subject to Carbonation with Application of Safety Factor Advances in Materials Science and Engineering 2018 pp. 1-10. https://doi.org/10.1155/2018/2430630

3. Yuan, Y., Ji, Y., Jiang, J. Effect of Corrosion Layer of Steel Bar in Concrete on Time-Variant Corrosion Rate Materials and Structures 42 2009: pp. 1443-1450. https://doi.org/10.1617/s11527-008-9464-9

4. Kumar, V., Singh, R., Quraishi, M. A Study on Corrosion of Reinforcement in Concrete and Effect of Inhibitor on Service Life of RCC Journal of Materials and Environmental Science 4 (5) 2013: pp. 726-731.

5. Kosmatka, H., Kerkhoff, B., Panarese, C. Design and Control of Concrete Mixtures Portland Cement Association Skokie, Illinois, USA 5420 2002: pp. 60077-1083.

6. Trejo, D., Pillai, G. Accelerated Chloride Thresholtesting: Part i-astm a 615 and a 706 Reinforcement Materials Journal 100 (6) 2003: pp. 519-527.

7. Chandio, A.D., Saleem, M.H., Khan, H.R., Hyder, I.N., Ali, M. Modified Zinc Oxide Nanoparticles for Corrosion Resistance Applications Journal of the Chemical Society of Pakistan 42 (05) 2020: pp. 705-712.

8. Palanivelu, R., $\quad$ Rajendran, V., $\quad$ Dhineshbabu, N.R., Palanisamy, T., Balasubramanian, S. Comparative Study of Addition of Amorphous Nanosilica Particles with Different Grades of Cement Mortar International Journal of Applied Ceramic Technology 12 (s3) 2014: pp. E14-E22. https://doi.org/10.1111/ijac.12349

9. Haider, S., $\quad$ Hafeez, I., $\quad$ Zaidi, S.B.A., $\quad$ Nasir, M.A., Rizwan, M. A Pure Case Study on Moisture Sensitivity Assessment Using Tests on Both Loose and Compacted Asphalt Mixture Construction and Building Materials 239 2020: pp. 11781. https://doi.org/10.1016/j.conbuildmat.2019.117817

10. Ferraris, C.F., Stutzman, P.E., Snyder, K.A. Sulphate Resistance of Concrete: A New Approach, R\&D Portland Cement Association, Skokie, Illinois, USA 2486 2006: p. 93.

11. Al-ansary, M., Lyengar, S.R. Physiochemical Characterization of Coarse Aggregates in Qatar for Construction Industry International Journal of Sustainable Built Environment 2 (1) 2013: pp. 27-40. https://doi.org/10.1016/j.ijsbe.2013.07.003

12. Bahoria, B.V., $\quad$ Parbat, D.K., $\quad$ Nagarnaik, P.B. Characterization Study of Natural Sand, Quarry Dust, Waste Plastic (LDPE) to be Used as a Fine Aggregate in Concrete International Journal of Civil Engineering and Technology 8 (3) 2017: pp. 391-401.

http://www.iaeme.com/ijciet/issues.asp?jtype=ijciet\&vtype= 8\&itype $=3$

13. Ismail, K.N., Hussin, K., Idris, M.S. Physical, Chemical and Mineralogical Properties of Fly Ash Journal of Nuclear and Related Technologies 40 (21) 2007: pp. 47-51.

14. Ramakrishnaiah, C.R., Sadashivaiah, C., Ranganna, G. Assessment of Water Quality Index for the Groundwater in
Tumkur Taluk, Karnataka State, India

E-journal of Chemistry 6 (2) 2009: pp. 523-530.

15. Bhikshma, V., Nitturkar, K., $\quad$ Venkatesham, Y. Investigations on Mechanical Properties of High Strength Silica Fume Concrete Asian Journal of Civil Engineering (Building and Housing) 10 2009: pp. 335-346.

16. Safiuddin, M.D., Hearn, N. Comparison of ASTM saturation Techniques for Measuring the Permeable Porosity of Concrete Cement and Concrete Research 35 (5) 2005: pp. $1008-1013$. https://doi.org/10.1016/j.cemconres.2004.09.017

17. Chandio, A.D., Abro, S.H. Effect of Temperature and Time on Nickel Aluminide Coating Deposition Mehran University Research Journal of Engineering \& Technology 37 (4) 2018: pp. 491-496.

18. Abro, S.H., Moria, H.A., Chandio, A., Al-Khazaal, A.Z. Understanding the Effect of Aluminum Addition on Forming the Second Phase Particles on Grain Growth of MicroAlloyed Steel Journal of Engineering, Technology \& Applied Science Research 10 (1) 2020: pp. 5153-5156.

19. Abro, S.H., Chandio, A.D., Abdulaziz, S.A., Channa, I.A. Role of Automotive Industry in Global Warming Pakistan Journal of Scientific \& Industrial Research Series A: Physical Sciences 62A (3) 2019: pp. 197-201.

20. Abro, S.H., Chandio, A.D., Umair, A. Effect of Heating Rate on Microstructural Developments in Cold Heading Quality Steel Used for Automotive Applications Mehran University Research Journal of Engineering \& Technology 37 (3) 2018: pp. $461-466$.

21. Abro, S.H., Shah, A.A., Chandio, A.D., Blundell, R. Effect of $\mathrm{Al}, \mathrm{Ni}, \mathrm{Mo}, \mathrm{Ti}, \mathrm{Nb}$ and Temperature on Grain Size Number in Low Carbon High Alloyed Steel Sindh University Research Journal-SURJ (Science Series) $51(1)$ 2018: pp. 59-64.

22. Abro, S.H., Shah, A.A., Abdulaziz, S.A., Shoaib, T. Ageing Analysis of Power Cablele Used in Nuclear Power Plant mehran University Research Journal of Engineering \& Technology 39 (1) 2020: pp. 2413-7219.

23. Chandio, A.D., Ansari, M.B., Abro, S.H. Silicon Carbide Effect as Reinforcement on Aluminum Metal Matrix Composite Journal of the Chemical Society of Pakistan 41 (4) 2019: pp. 650-654.

24. Abro, S.H., Chandio, A.D., Moria, H.A. Findings of Grain Coarsening Temperature and Grain Growth of Light Weight Steel Used in Automotive Industry Pakistan Journal of Engineering and Applied Sciences 25 2019: pp. 14-17.

25. Abro, S.H. A Role of Mn Atoms on Tensile Properties of Light Weight CHQ Steel Journal of Engineering and Applied Sciences 38 (1) 2019: pp. 69-74.

26. Mehdi, M., Akhtar, M., Abro, S.H. Electrochemical Synthesis of AgNP and Mechanical Performance of AgNPEG Journal of Elastomers and Plastics 1 (11) 2019: pp. 240-245.

27. Abro, S.H., Hanif, S., Kandhro, F.H. On the Effect of Austenite Formation Kinetics on Microstructural Features of Cold Heading Quality CHQ Steel NUST Journal of Engineering Sciences 13 (1) 2020: pp. 2. License (http://creativecommons.org/licenses/by/4.0/), which permits unrestricted use, distribution, and reproduction in any medium provided you give appropriate credit to the original author(s) and the source, provide a link to the Creative Commons license, and indicate if changes were made. 